\title{
HUBUNGAN PERILAKU IBU MENYUSUI TERHADAP TEKNIK MENYUSUI YANG BENAR DI BIDAN PRAKTIK SWASTA ELIDA FITRI KECAMATAN BLANGPIDIE ACEH BARAT DAYA 2014
}

\author{
Lia Anggraini ${ }^{1}$, Yuliatul Muslimah ${ }^{2}$ \\ Fakultas Kesehatan Masyarakat, Universitas Teuku Umar, Aceh Barat, Indonesia
}

\begin{abstract}
ABSTRAK
Kehamilan, persalinan dan menyusui merupakan proses fisiologi yang perlu dipersiapkan oleh wanita dari pasangan subur agar dapat di lalui dengan aman. Teknik menyusui yang benar perlu dipelajari oleh setiap ibu bukan hanya ibu yang pertama kali melahirkan juga ibu yang pernah menyusui anaknya. Ini disebabkan setiap bayi yang lahir individu tersendiri. Dengan demikian ibu perlu belajar berinteraksi dengan manusia baru agar dapat sukses dalam memberikan yang terbaik bagi bayinya. Pada sebagian ibu yang tidak paham tentang teknik menyusui yang benar kegagalan menyusui sering dianggap sebagai problem pada anaknya saja, selain itu ibu sering mengeluh bayinya sering menangis atau menolak menyusui, diartikan bahwa asinya tidak cukup. Penelitian ini merupakan Penelitian analitik dengan Desain Cross Sectional dengan jumlah populasi 187 Ibu menyusui, dan sampel dalam Penelitian ini sebanyak yaitu 65 Ibu menyusui di Bidan Praktek Swasta Elida Fitri Kecamatan Blang Pidie Aceh Barat Daya.
\end{abstract}

Hasil penilitian ini didapatkan dari uji statistik adanya hubungan antara pengetahuan terhadap tehnik penyusui yang benar dimana $P$. Value 0,01 yang berarti lebih kecil dari 0,05 , ada hubungan antara sikap terhadap tehnik menyusui yang benar dengan $P$. Value 0,04 berarti lebih kecil dari 0,05 , ada hubungan antara tindakan terhadap tehnik menyusui yang benar di mana $P$. Value 0,00 lebih kecil dari 0,05. Penulis menyarankan bagi Dinas Kesehatan Aceh Barat Daya dapat memberikan penyuluhan kepada ibu menyusui agar ibu dapat mengetahui tentang tehnik menyusui yang benar. Diharapkan kepada pihak Pukesmas dan Klinik Swasta yang ada hendaknya menyediakan sarana dan Poster-poster serta buku baca yang berkaitan dengan Pengetahuan Teknik menyusui.

Kata Kunci : Pengetahuan, Sikap, Tindakan dan Teknik Menyusui

Kehamilan, persalinan dan menyusui merupakan proses fisiologi yang perlu di persiapkan oleh wanita dari pasangan subur agar dapat dilalui dengan aman. Teknik menyusui yang benar perlu di pelajari oleh setiap ibu bukan hanya ibu yang pertama kali melahirkan juga ibu yang pernah menyusui anaknya. Ini disebabkan setiap bayi yang lahir individu tersendiri. Dengan demikian ibu perlu belajar berinteraksi dengan 
"manusia baru" ini agar dapat sukses dalam memberikan yang terbaik bagi bayinya (Ambarwati, 2009).

Teknik menyusui yang benar perlu di pelajari oleh setiap ibu bukan hanya ibu yang pertama kali melahirkan juga ibu yang pernah menyusui anaknya. Ini disebabkan setiap bayi yang lahir individu tersendiri (Huliana, 2005). Pengalaman dalam upaya meningkatkan penggunaan ASI, selama 15 tahun menunjukkan bahwa hambatan utama penggunaan ASI adalah kurang sampainya pengetahuan yang benar tentang ASI dan menyusui pada para ibu. ASI dan menyusui umumnya dianggapa hal yang biasa yang tidak perlu dipelajari, manajemen laktasi atau cara menyusui yang kurang tepat, adanya mitos-mitos yang menyesatkan yang sering menghambat pemberian ASI (Roesli utami, 2007).

Teknik menyusui yang benar adalah cara memberikan asi kepada bayi dengan perlekatan dan posisi ibu dan bayi dengan benar ( Perinasia, 2008). Menyusui merupakan salah satu komponen dari proses reproduksi yang terdiri atas haid, konsepsi, kehamilan, persalinan, menyusui, dan penyapihan. Jika semua komponen berlangsungndengan baik, proses menyusui akan berhasil (Prawirohardjo, 2008). Menyusui akan sukses bila posisi menyusui itu benar. Ini berarti, posisi tubuh dan cara memegang bayi membuat ibu dan bayi sama-sama nyaman (Eiastman, A, 2006)

Dari hasil penelitian digolongkan bahwa berbagai faktor yang dapat mempengaruhi keberhasilan laktasi yaitu, faktor ibu 39,7 \%, faktor bayi 36,7\%, teknik menyusui $22,1 \%$, faktor anatomis payudara $1,5 \%$. Pada dasarnya gangguan laktasi tersebut dapat dicegah dan diatasi sehingga tidak menimbulkan kesukaran. Suatu contoh kasus misalnya sekitar $57 \%$ dari ibu menyusui menderita kelecetan putingnya (Kristiyanasari, 2009). Selanjutnya $d r$. Josep Budi, S.SPA mengatakan meskipun menyusui itu mudah, namun ibu - ibu yang memiliki bayi harus tetap memahami teknik menyusui bayi yang baik dan benar banyak ibu yang menyusui bayinya, namun tidak banyak yang menyusui dengan sukses (Huliana, 2007).

Menurut laporan badankesehatan dunia (WHO) mencatat bahwa angka ibu nifas meningkat tiap tahunnya. Pada tahun 2013 tercatat ada 2.928 .868 jiwa ibu nifas. Menurut hasil laporan dinas kesehatan provinsi nanggroe aceh darussalam pada tahun 2013 tercatat ada sekitar 100.486 jiwa ibu nifas (Dinkes Provinsi Aceh 2013). Berdasarkan data yang diperoleh dari Dinas Kesehatan Aceh Barat Daya jumlah ibu 
menyusui ada 1.486 jiwa pada tahun 2014 (data dari januari-agustus). Sedangkan data ibu menyusui di puskesmas Blangpidie pada Januari-Agustus 2014 ada 421 orang ibu menyusui(Dinkes Aceh Barat Daya 2014).

Berdasarkan data yang diperoleh dari Bida n praktik swasta Elida Fitri tahun 2013 (periode Januari - Desember), ibu nifas yang berkunjung yaitu sebanyak 187 orang. Berdasarkan hasil observasi dan wawancara pada 12 orang ibu nifas didapatkan hasil bahwa ibu yang mempunyai pengetahuan rendah tentang teknik menyusui sebanyak 9 orang dan yang berpengetahuan tinggi 3 orang. Berdasarkan pengalaman saya melihat bahwa banyak ibu-ibu yang baru melahirkan mengalami banyak kesalahan dalam melakukan teknik menyusui maupun posisi menyusui yang mengakibatkan nyeri pada putting saat menyusui, putting susu menjadi lecet, asi tidak keluar secara optimal, dan payudara ibu bengkak. Maka dari pengalaman inilah saya tertarik untuk melakukan penelitain di Bidan praktik swasta Elida Fitri.

\section{Metodologi Penelitian}

Penelitian ini merupakan penelitian yang menggunakan metode survei analitik yang bertujuan untuk melihat atau mencari hubungan antara variabel independen dengan variabel dependen yaitu hubungan pengetahuan, sikap, tindakan terhadap tehnik menyusui yang benar sebagaimana yang terdapat dalam kerangka konsep.Penelitian ini merupakan penelitian kuantitatif yang jenisnya analitik dengan desain Cross Sectional dimana variabel bebas dan variabel terikat yang terjadi pada obyek penelitian di observasi dan di ukur dalam waktu yang bersamaan untuk mengetahui ada tidaknya hubungan dari keduanya (Notoatmodjo, 2005).

Lokasi penelitian di klinik swasta Elida Fitri dipilih karena jumlah ibu menyusui yang berkunjung lebih banyak dari klinik swasta lainnya yang ada di Kecamatan Blang pidie. Waktu Penelitian ini dilakukan pada tanggal 15-22 November 2014.

Populasi adalah seluruh objek penelitian atau objek yang diteliti (Notoadmojo, 2010). Dalam penelitian ini jumlah objeknya 187 ibu menyusui mulai dari Januari Oktober 2014. Pengambilan sampel dilakukan dengan cara Purposive Sampling, yaitu dilakukan dengan mengambil responden berdasarkan kriteria responden (Notoadmojo, 2010). Jumlah sampel dalam penelitian ini adalah 65 ibu menyusui yang berkunjung ke bidan Praktik Elida Fitri Kecamatan Blang Pidie Kabupaten Aceh Barat Daya. 


\section{Hasil dan Pembahasan}

Hasil

Klinik Elida Fitri merupakan salah satu Klinik yang di dirikan pada tanggal 14 Februari Tahun 2006 di Kecamatan Blang Pidie Kabupaten Aceh Barat Daya, dengan jumlah tenaga kerja yaitu 2 orang. Dengan batas-batas klinik adalah sebagai berikut Utara berbatasan dengan Desa Gudang, Selatan berbatasan dengan Gunung Kodim, Timur berbatasan dengan Desa Lamkuta ,Barat berbatasan dengan Desa Keude Paya.

Tabel 1 Distribusi Frekuensi umur Ibu menyusui yang benar di Bidan Praktek Swasta Elida Fitri Kecamatan Blang Pidie Kabupaten Aceh Barat Daya.

\begin{tabular}{rlll}
\hline No & \multicolumn{1}{c}{ Umur } & f & \% \\
\hline 1 & TUA $(36-43)$ & 16 & 24,6 \\
2 & MUDA $(18-35)$ & 49 & 75,4 \\
\hline Total & $\mathbf{6 5}$ & $\mathbf{1 0 0}$ \\
\hline
\end{tabular}

Tabel 2 Distribusi Frekuensi Pendidikan Ibu menyusui yang benar di Bidan Praktek Swasta Elida Fitri Kecamatan Blang Pidie Kabupaten Aceh Barat Daya.

\begin{tabular}{cccc}
\hline No & Pendidikan & f & \% \\
\hline 1 & SD & 29 & 44,6 \\
2 & SLTP & 26 & 40,0 \\
3 & SMA & 6 & 9,2 \\
4 & SARJANA & 4 & 6,2 \\
\hline & Total & $\mathbf{6 5}$ & $\mathbf{1 0 0}$ \\
\hline
\end{tabular}

Tabel 3 Distribusi Frekuensi Jumlah Anak Ibu menyus ui yang benar di Bidan Praktek Swasta Elida Fitri Kecamatan Blang Pidie Kabupaten Aceh Barat Daya.

\begin{tabular}{cccc}
\hline No & Jumlah Anak & f & \% \\
\hline 1 & Satu & 34 & 52,4 \\
2 & Dua & 22 & 33,8 \\
3 & Tiga dan Seterusnya & 9 & 13,8 \\
\hline & Total & $\mathbf{6 5}$ & $\mathbf{1 0 0}$
\end{tabular}


Tabel 4 Distribusi Frekuensi Pekerjaan Ibu meny usui yang benar di Bidan Praktek Swasta Elida Fitri Kecamatan Blang Pidie Kabupaten Aceh Barat Daya.

\begin{tabular}{llll}
\hline No & Pekerjaan & f & \% \\
\hline 1 & IRT & 51 & 78,4 \\
2 & PNS & 8 & 12,3 \\
3 & WIRASWASTA & 6 & 9,3 \\
\hline & Total & $\mathbf{6 5}$ & $\mathbf{1 0 0}$ \\
\hline
\end{tabular}

Pengetahuan Teknik Menyusui yang benar

Tabel 5 Distribusi Frekuensi pengetahuan di klinik Elida Fitri Kecamatan Blang Pidie Kabupaten Aceh Barat Daya

\begin{tabular}{lllcc}
\hline No & & Pengetahuan & F & \% \\
\hline 1 & Baik & & 23 & 35,4 \\
2 & Kurang baik & 42 & 64,6 \\
\hline \multicolumn{2}{l}{ Jumlah } & $\mathbf{6 5}$ & $\mathbf{1 0 0}$ \\
\hline
\end{tabular}

Sumber: data primer,2014 (diolah)

Sikap

Tabel 6 Distribusi Frekuensi sikap di Klinik Elida Kecamatan Blang Pidie Kabupaten Aceh Barat Daya Tahun 2014

\begin{tabular}{llccc}
\hline No & & Sikap & F & \% \\
\hline 1 & Negatif & 41 & 63,1 \\
2 & Positif & 24 & 36,9 \\
\hline & Jumlah & $\mathbf{6 5}$ & $\mathbf{1 0 0}$ \\
\hline
\end{tabular}

Sumber: data primer,2014 (diolah)

Tindakan

Tabel 7 Distribusi Frekuensi Tindakan di Klinik Elida Kecamatan Blang Pidie Kabupaten Aceh Barat Daya Tahun 2014

\begin{tabular}{llccc}
\hline No & & Tindakan & f & \% \\
\hline 1 & Baik & 28 & 43,1 \\
2 & Kurang baik & 37 & 56,9 \\
\hline & Jumlah & $\mathbf{6 5}$ & $\mathbf{1 0 0}$ \\
\hline
\end{tabular}

Sumber: data primer,2014 (diolah)

Teknik Menyusui yang Benar

Tabel 8 Distribusi Frekuensi responden berdasarkan Teknik Menyusui yang Benar

\begin{tabular}{|c|c|c|c|}
\hline No & Teknik Menyusui & $\mathbf{f}$ & $\%$ \\
\hline 1 & Baik & 30 & 46,2 \\
\hline 2 & Kurang baik & 35 & 53,8 \\
\hline & Jumlah & 65 & 100 \\
\hline
\end{tabular}

Sumber: data primer,2014 (diolah) 
Hubungan Pengetahuan terhadap Teknik Menyusui yang Benar

Tabel 9 Distribusi Frekuensi Pengetahuan Terhadap Teknik Menyusui yang Benar di Klinik Elida Fitri Kecamatan Blang Pidie Kabupaten Aceh Barat Daya

\begin{tabular}{|c|c|c|c|c|c|c|c|c|c|}
\hline \multirow{3}{*}{ No } & \multirow{3}{*}{ Pengetahuan } & \multicolumn{4}{|c|}{ Teknik Menyusui } & \multicolumn{2}{|c|}{ Jumlah } & \multirow{3}{*}{$\begin{array}{c}\mathbf{P} \\
\text { Value }\end{array}$} & \multirow[t]{3}{*}{$\alpha$} \\
\hline & & \multicolumn{2}{|c|}{ Baik } & \multicolumn{2}{|c|}{ Kurang } & & & & \\
\hline & & $\mathbf{f}$ & $\%$ & $\mathbf{f}$ & $\%$ & $\mathbf{f}$ & $\%$ & & \\
\hline & Baik & 16 & 69,6 & 7 & 30,4 & 23 & 100 & & \\
\hline & Kurang baik & 14 & 46,2 & 28 & 66,7 & 42 & 100 & 0,011 & 0,05 \\
\hline & Jumlah & 30 & 46,2 & 35 & 53,8 & 65 & 100 & & \\
\hline
\end{tabular}

Sumber: data primer,2014(diolah)

Dari Tabel 4.9 diatas dapat disimpulkan bahwa 23 responden memiliki pengetahuan baik diantaranya terdapat $16(69,6 \%)$ responden yang teknik menyusuinya baik dan teknik menyusuinya kurang 7 (30,4\%), sedangkan 42 responden memiliki pengetahuan kurang baik diantaranya teknik menyusui baik 14 (46,2\%) dan responden memiliki teknik menyusui kurang 28 (66,7\%).

Setelah dilakukan uji statistik dengan menggunakan uji chi-square dengan taraf kepercayaan 95\% ( $\alpha$ 0,05). Diperoleh nilai p-value 0,011 yang berarti lebih kecil dari nilai $\alpha(0,05)$. Dengan demikian dapat ditarik kesimpulan bahwa terdapat hubungan yang sangat signifikan antara pengetahuan terhadap teknik menyusui yang benar.

Hubungan Sikap terhadap Teknik Menyusui yang Benar

Tabel 10 Distribusi Frekuensi Sikap Terhadap Teknik Menyusui yang Benar di Klinik Elida Fitri Kecamatan Blang Pidie Kabupaten Aceh Barat Daya

\begin{tabular}{|c|c|c|c|c|c|c|c|c|c|}
\hline \multirow{3}{*}{ No } & \multirow{3}{*}{ Sikap } & \multicolumn{4}{|c|}{ Teknik Menyusui } & \multicolumn{2}{|c|}{ Jumlah } & \multirow[t]{3}{*}{$\begin{array}{c}P \\
\text { Value }\end{array}$} & \multirow[t]{3}{*}{$\alpha$} \\
\hline & & \multicolumn{2}{|c|}{ Baik } & \multicolumn{2}{|c|}{ Kurang } & & & & \\
\hline & & $\mathbf{f}$ & $\%$ & $\mathbf{f}$ & $\%$ & $\bar{f}$ & $\%$ & & \\
\hline & Negatif & 25 & 61,0 & 16 & 39,0 & 41 & 100 & & \\
\hline & Positif & 5 & 20,8 & 19 & 79,2 & 24 & 100 & 0,004 & 0,05 \\
\hline & Jumlah & 30 & 46,2 & 35 & 53,8 & 65 & 100 & & \\
\hline
\end{tabular}

Sumber: data primer,2014 (diolah)

Dari Tabel 4.10 di atas dapat disimpulkan bahwa 41 responden memiliki sikap negatif teknik menyusuinya baik $25(61,0 \%)$ dan teknik menyusuinya kurang 16 $(39,0 \%)$, sedangkan 24 responden memiliki sikap positif teknik menyusuinya baik 5 $(20,8 \%)$ dan teknik menyusuinya kurang $19(79,2 \%)$. 
Setelah dilakukan uji statistik dengan menggunakan uji chi-square dengan taraf kepercayaan 95\% ( $\alpha 0,05)$. Diperoleh nilai $p$-value 0,004 yang berarti lebih kecil dari nilai $\alpha(0,05)$. Dengan demikian dapat ditarik kesimpulan bahwa terdapat hubungan yang sangat signifikan antara sikap terhadap teknik menyusui yang benar.

Hubungan Tindakan terhadap Teknik Menyusui yang Benar

Tabel 11 Distribusi Frekuensi Terhadap Teknik Menyus ui yang Benar di Klinik Elida Fitri Kecamatan Blang Pidie Kabupaten Aceh Barat Daya

\begin{tabular}{|c|c|c|c|c|c|c|c|c|c|}
\hline \multirow{3}{*}{ No } & \multirow{3}{*}{ Tindakan } & \multicolumn{4}{|c|}{ Teknik Menyusui } & \multicolumn{2}{|c|}{ Jumlah } & \multirow{3}{*}{$\begin{array}{c}P \\
\text { Value }\end{array}$} & \multirow[t]{3}{*}{$\mathbf{A}$} \\
\hline & & \multicolumn{2}{|c|}{ Baik } & \multicolumn{2}{|c|}{ Kurang } & & & & \\
\hline & & $\mathbf{f}$ & $\%$ & $\mathbf{f}$ & $\%$ & $\mathbf{f}$ & $\%$ & & \\
\hline & Baik & 23 & 82,1 & 5 & 17,9 & 28 & 100 & & \\
\hline & Kurang baik & 7 & 18,9 & 30 & 81,1 & 37 & 100 & 0,000 & 0,05 \\
\hline & Jumlah & 30 & 46,2 & 35 & 53,8 & 65 & 100 & & \\
\hline
\end{tabular}

Sumber: data primer,2014 (diolah)

Dari Tabel 4.11 di atas dapat disimpulkan bahwa 28 responden memiliki tindakan baik teknik menyusuinya baik $23(82,1 \%)$ dan teknik menyusui kurang 5 $(17,9 \%)$ sedangkan 37 responden memiliki tindakan kurang baik teknik menyusuinya baik $7(18,9 \%)$ dan teknik menyusuinya kurang $30(81,1 \%)$.

Setelah dilakukan uji statistik dengan menggunakan uji chi-square dengan taraf kepercayaan 95\% ( $\alpha 0,05)$. Diperoleh nilai p-value 0,000 yang berarti lebih kecil dari nilai $\alpha(0,05)$. Dengan demikian dapat ditarik kesimpulan bahwa terdapat hubungan yang sangat signifikan antara tindakan terhadap teknik menyus ui.

\section{Pembahasan}

\section{Hubungan Pengetahuan Terhadap Teknik Menyusui yang Benar}

Hubungan pengetahuan terhadap teknik menyusui yang benar dapat dilihat pada tabel 4.5 yang berdasarkan hasil penelitian yang menggunakan Uji Chi-square menunjukkan ada nya hubungan yang bermakna antara pengetahuan terhadap teknik menyusui yang benar dengan nilai $\mathrm{p}$ value sebesar 0,011 . Hal ini menunjukkan bahwa $p$ $<\alpha(0,05)$. Berdasarkan hasil statistik nilai $\mathrm{p}$ value $=0,011$ ternyata nilai $\mathrm{p}$ value lebih kecil dari nilai $\alpha$ berarti Ha diterima artinya ada hubungan yang signifikan antara pengetahuan terhadap teknik menyusui yang benar. Pengetahuan disini adalah segala 
sesuatu yang diketahui responden tentang teknik menyusui yang benar (Notoadmojo, 2005) tingkat pengetahuan kedua adalah memahami suatu objek bukan hanya sekedar tahu terhadap objek tersebut tidak sekedar dapat menyebutkan tapi dapat menginterpretasikan secara benar.

Berdasarkan hasil penelitian dari 65 ibu-ibu menyusui yang menjadi responden diketahui bahwa responden dengan pengetahuan kurang baik terhadap teknik menyusui yang benar memiliki proporsi yang lebih besar yaitu 53,8\%. Hal ini disebabkan karena responden jarang mendapat penyuluhan kesehatan dari tenaga kesehatan baik di lingkungan tempat tinggal atau di saranan kesehatan. Menyusui akan sukses bila posisi menyusui ibu benar. Ini berarti, posisi tubuh dan cara memegang bayi membuat ibu dan bayi sama-sama nyaman.

Pengetahuan responden yang kurang baik harus ditingkatkan agar secara sadar ibu menyusui dengan sendirinya akan menerapkan segala sesuatu yang mereka ketahui tentang teknik menyusui yang benar. Peningkatan pengetahuan dapat dilakukan dengan memberikan penyuluhan secara teratur melalui sarana yang ada saat ini seperti media cetak, media elektronik, baliho dan leaflet. Peran tenaga kesehatan primer salah satunya adalah preventif atau pencegahan dapat difungsikan secara optimal. Kesadaran diri sendiri untuk mencari tahu tentang informasi teknik menyusui yang benar juga harus ditanamkan pada ibu hamil sehingga ketika bayi mereka lahir mereka dapat menyusui dengan baik dan benar. Hasil penelitian ini didukung oleh penilitian sebelumnya di bidan praktek swasta Sinarti banda aceh yang menyatakan bahwa pengaruh tingkat pendidikan ibu terhadap pengetahuan tentang tehnik menyusui yang benar.

\section{Hubungan Sikap terhadap Teknik Menyusui yang Benar}

Hubungan sikap terhadap teknik menyusui dapat dilihat pada tabel 4.6 yang berdasarkan hasil penelitian yang menggunakan Uji Chi-square menunjukkan bahwa ada hubungan yang bermakna antara sikap responden terhadap teknik menyusui yang benar dengan nilai $\mathrm{p}$ value 0,004 . Hal ini menunjukkan bahwa $p<\alpha(0,05)$.

Faktor yang mempengaruhi pembentukansikap, menurut Walgito (2003) adalah faktor pengetahuan. Menurut Notoatmodjo (2007),sikap merupakan kesiapan untuk bereaksi terhadap objek di lingkungan tertentu sebagaisuatu penghayatan terhadap objek. Hasil penelitian ini sejalan dengan penelitian yang dilakukan oleh Rohani (2007) 
terhadap ibu menyusui yang berkunjung ke Puskesmas Telul Langkat, tentang pengaruh karakteristik ibu menyusui terhadap ASI menunjukan bahwa 61,7\% ibu memiliki sikap negatif terhadap tehnik menyusui yang benar.

Menurut(Walgito, 2003) sikap sangat berkaitan erat dengan tingkat pengetahuan seseorang. Sikap seseorang terhadap suatu objek menunjukkan pengetahuan orang tersebut terhadapobjek yang bersangkutan. Dengan demikian dapat diambil kesimpulan bahwa ibu-ibuyang mempunyai pengetahuan baik terhadap teknik menyusui, maka mereka akancenderung mempunyai sikap positif. Sebaliknya ibu yang kurang pengetahuannyaterhadap teknik menyusui cenderung mempunyai sikap negatif sikap.

Sugeng Hariyadi (2003) juga berpendapat bahwa sikap merupakan penentu penting dalam tingkah laku. Sikap yang ada pada seseorang akan memberikan gambaran corak bagaimana tingkah laku seseorang. Dari mengetahui sikap seseorang, orang akan dapat menduga bagaimana respon atau tindakan yang akan diambil oleh orang tersebut terhadap suatu masalah atau keadaan yang dihadapinya. Sikap responden yang dominan kurang baik tersebut dalam hal teknik menyusui merupakan proses penilaian responden pada hal-hal berkaitan dengan teknik menyusui. Sikap dapat dipandang sebagai prediposisi untuk beraksi dengan cara yang menyenangkan atau tidak menyenangkan terhadap objek,orang dan konsep apa saja. Adapun beberapa asumsi yang mendasari pendapatan terrsebut, yaitu sikap berhubungan dengan prilaku,sikap yang berkaitan erat dengan seseorang terhadap objek dan sikap adalah kontruksi yang bersifat hipotesis,artinya dapat diamati,tetapi sikap itu tidak dapat dipahami,

Pengetahuan orang terhadap teknik menyusui dapat berbeda-beda walaupun ia hidup dalam masyarakat yang sama. Perbedaaan ini dapat terjadi karena perbedaan pendidikan, akses terhadap sumber informasi, dan kemampuan orang untuk menyerap informasi yang didapatkan. Kemudian, pengetahuan yang telah didapat itu belum tentu diterapkan dalam kehidupan sehari-hari.

\section{Hubungan Tindakan terhadap Teknik Menyusui yang Benar}

Tindakan dengan teknik menyusui yang benar dapat dilihat pada Tabel 7 yang berdasarkan hasil penelitian yang menggunakan Uji Chi-square menunjukkan adanya 
hubungan yang bermakna antara tindakan terhadap teknik menyusui yang benar dengan nilai $\mathrm{p}$ value sebesar 0,000 . Hal ini menunjukkan bahwa $p<\alpha(0,05)$.

Tindakan adalah aturan yang dilakukan, melakukan/mengadakan aturan-aturan untuk mengatasi sesuatu atau perbuatan. Adanya hubungan yang erat antara sikap dan pengetahuan merupakan kecenderungan untuk bertindak. Tindakan nampak menjadi lebih konsisten, serasi, sesuai dengan sikap bila sikap individu sama dengan sikap kelompok dimana ia adalah bagiannya atau anggotanya (Purwanto, 1999).

\section{Kesimpulan}

Dari hasil penelitian sebagian besar responden memiliki pengetahuan kurang baik tentang teknik menyusui yang benar sebanyak 42 orang $(64,6 \%)$, sebagian besar responden memiliki sikap yang negatif terhadap tehnik menyusui yang benar yaitu sebanyak $41(63,1 \%)$, dan responden yang tindakan kurang baik paling banyak yaitu 37 $(56,9 \%)$.

Terdapat hubungan yang signifikan antara pengetahuan terhadap Teknik Menyusui yang benar di Klinik Elida Fitri Kecamatan Blang Pidie Kabupaten Aceh Barat Daya Tahun $2014(\mathrm{p}=0,011<\alpha=0,05)$. Terdapat hubungan yang signifikan antara sikap terhadap Teknik Menyusui yang benar di Klinik Elida Fitri Kecamatan Blang Pidie Kabupaten Aceh Barat Daya Tahun 2014 ( $\mathrm{P}=0,014<\alpha=0,05)$. Terdapat hubungan yang signifikan antara tindakan terhadap teknik menyusui yang benar di Klinik Elida Fitri Kecamatan Blang Pidie Kabupaten Aceh Barat Daya Tahun 2014 (P = $0,000<\alpha=0,05)$.

Berdasarkan hasil penelitian di ketahui ada hubungan antara motivasi kerja dengan kepuasan kerja perawat pada program Jaminan Kesehatan Nasional di BLUD Teungku Peukan Kabupaten Aceh Barat Daya Tahun 2014 bahwa Pvalue $(0,020)<\alpha$ $(0,05)$ artinya ada hubungan yang signifikan antara motivasi kerja dengan tingkat kepuasan kerja perawat. 


\section{Daftar Pustaka}

Ambarwati Eny Retna, Wulandari Diah. 2009. Asuhan Kebidanan Nifas, Mitra Cendika, Yogyakarta.

Arikunto, Suharsimi. 2010. Prosedur Penelitian Edisi Revisi Cetakan 14. Rineka Cipta, Jakarta

Dinkes, 2013, Profil Kesehatan Aceh Barat Daya.

Dinkes Provinsi Aceh 2013.Profil Kesehatan Dinas Kesehatan Provinsi Aceh,Dinkes Prov Aceh.

Huliana, 2005. Perawatan Ibu Pasca Melahirkan. Puspa Swara, Jakarta

Hariadi, 2003. Psikologi Perkembangan. Semarang

Irmayanti, 2011. Tentang Hubungan Tingkat Pengetahuan Dengan Tindakan Menyusui Yang Baik dan Benar Pada Ibu

Kristiyanasari, weni. 2009. ASI Menyusui dan sadari, Yogyakarta : Nuha medika

Notoatmodjo, S. 2005.MetodologiPendidik an Kesehatan. Jakarta:RinekaCipta

Notoadmojo, Soekidjo. 2007. Metodologi Penelitian Kesehatan Edisi Revisi. Jakarta : Rineka Cipta

Notoadmojo, Soekidjo. 2010. Metodologi Penelitian Kesehatan Edisi Revisi. Jakarta : Rineka Cipta

Perinesia.(2008).BahanBacaan danPetunjuk PraktisPerawatanBayi BeratLahir Rendah denganMetodeKanguru.Perkumpulan Perinatologi Indonesia (Perinesia).

Purwanto,1999. Pengantar perilaku manusia untuk keperawatan. Jakartas

Rahmawati Anita, Widyasih Hesti, Suherni. 2009. Perawatan Masa Nifas. Yogyakarta : Fitramaya

Roesli Utami. 2009. Mengenal ASI Eksklusif. Jakarta: Trubus Agriwidya

Rohani. 2007. Pengaruh Kateristik Ibu Menyusui terhadap pemberian ASI eksklusif di wilayah kerja puskesmas Telul Kecamatan Seucanggang Kabupaten Langkat, 2009 Skripsi.

Saleha, Siti. 2009. Asuhan Kebidanan Pada Masa Nifas. Jakarta : Salemba Medika 
Safitri, 2010 Gambaran Pengetahuan Ibu Menyusui tentang Teknik Menyusui yang Benar di Bidan Praktek Swasta

Sarwono, 2008, Sosiologi Kesehatan, Gajah Mada Jogyakarta

Slameto, 2009, Faktor-faktor Mempengaruhi Prestasi Belajar, Jakarta, Usaha, Usaha Nasional

Sunjana. 2005. Metode statistika. Bandung : Tarsito.

WHO/Unicef,2013. Pedoman Hidup Sehat. Cetakan Ulang Kesehatan Republik Indonesia

Walgito, 2003, Psikologi sosial (suatu pengantar), ed.IV, Yogyakarta : C.V.Andi offset. 